\title{
Mineralogical and morphometric aspects of the rock analysis as the basis for choosing a scheme for ore preparation
}

\author{
Asiya Duryagina ${ }^{1 *}$, Gerhard Heide $^{2}$, Irina Talovina ${ }^{1}$, and Arturo Bravo ${ }^{2}$ \\ ${ }^{1}$ Saint Petersburg Mining University, Department of Historical and Dynamic Geology, 199106 St. \\ Petersburg, Russia, 21 line, 2. \\ ${ }^{2}$ TU Freiberg Mining Academy, Institute of Mineralogy, D-09599 Freiberg, Germany, \\ Brennhausgasse 14 .
}

\begin{abstract}
Annotation. The complexity of deep processing of fine-grained and refractory mineral raw materials is determined by the difficulty of disclosing aggregates of ore components during disintegration and extracting them into commercial products of standard quality. The main task of the disintegration of such ores is to destroy the object along the phase boundaries without overgrinding while minimizing energy costs. To implement selective disintegration, a precise study of the properties of the mineral components of the ore is necessary. However, there are no systematic data on the effect and relationship of the mineralogicaltechnological, structural-textural and physical-technical properties of minerals, rocks and ores with the processes of selective disintegration. The article presents the results of computer microtomographic and opticalmicroscopic studies of the structural and textural characteristics of typical sulfide copper-nickel ores using a SkyScan-1173 microtomograph from Bruker (Belgium), as well as a specialized, accredited as a measuring tool, Thixomet Pro software (Russia). The studies made it possible to identify automatically 19 morphometric parameters of ore grains in three mutually perpendicular sections, the most informative of which were the grain size of individual ore minerals, their perimeter, distance between grains and grain shape (sphericity, edge roughness, and others). The obtained quantitative characteristics of the structural and textural parameters, the analysis of the granulometric composition of the grains of ore minerals make it possible to assess the possibility of using selective grinding at various stages of ore preparation.

Keywords. Computer X-ray microtomography, sulfide copper-nickel ores, selective grinding, quantitative structural and textural parameters, technological mineralogy, ore preparation.
\end{abstract}

\section{Introduction}

The increasing of refractory raw materials in the ore processing requires the development of new approaches and processing technologies. The disintegration processes used at the first

\footnotetext{
*Main author: talovina_iv@pers.spmi.ru
} 
stage of refractory ore dressing make it possible to extract valuable components without significant environmental damage, that increase the profitability of ore processing and development of deposits in general [1,2]. At the moment, scientifically based approaches to the creation of rational, flexible technological schemes and processes for processing refractory natural ores have not yet been developed. The complexity of deep processing of fine-grained sulfide ores is determined by the difficulty of disclosing aggregates of valuable components during disintegration and extracting them into commercial products of standard quality $[3,4]$. The main task of the disintegration of refractory ores is to destroy the object along the phase boundaries without overgrinding while minimizing energy consumption [5]. Currently known devices and methods do not provide sufficient disclosure of grains of valuable components in finely disseminated mineral raw materials, while the destruction of the material occurs in bulk. This leads to the loss of valuable components and reduces the technological indicators of further enrichment and processing of finely disseminated, refractory ores, placers and technogenic formations. The problem of improving the quality of concentrates is closely associated with the development of scientific foundations for the disclosure of finely disseminated mineral inclusions due to selective disintegration, increasing the selectivity of the separation of mineral complexes, increasing the efficiency of gravitational and magnetic enrichment methods, as well as studying the relationship of the structural, material and phase composition with the physical, physicochemical and technological properties of minerals, a combination of methods of physicochemical and mathematical modeling of processes of disintegration and separation of minerals with experimental research, the development of the theory of intergranular destruction of mineral complexes.

To implement selective disintegration, a precise study of the properties of the mineral components of the ore is necessary. However, systematic data on the influence and relationship of the mineralogical-technological, structural-textural and physical-technical properties of minerals, rocks and ores with the processes of selective disintegration are still lacking. Usually geologists describe the texture and structure of ore formations by analyzing thin sections or polished sections [6]. This method has limitations, since it is twodimensional and can only give a qualitative description. For more detailed information, incl. quantitative information about mineral raw materials, it is necessary to find the relationship between the corresponding parameters of destruction, product characteristics and their inherent mineralogical, technological and structural and textural features, which is also an urgent task in the study of selective disintegration processes and the development of devices for their implementation $[7,8]$.

\section{Experimental research technique}

Within the framework of this study, the morphometric parameters of typical samples of copper-nickel ores were studied by computer X-ray microtomography and these data were compared with the results of optical microscopic studies.

X-ray tomographic studies and visualization of the internal three-dimensional structure of oriented samples (Fig. 1) were carried out using a SkyScan-1173 microtomograph from Bruker (Belgium) equipped with certified programs NRecon, DataViewer, CTAn, and CTVox. For the survey, rock cylinders $2 \mathrm{~cm}$ in diameter were sawn out. Shooting parameters: accelerating voltage $130 \mathrm{kV}$, current $60 \mathrm{~mA}$, resolution 17 microns, glass filter $0.25 \mathrm{~mm}$, rotation step $0.3 \mathrm{deg}$. The method is based on reduction of the power of X-ray radiation when it passes through a certain sample volume due to absorption of $\mathrm{X}$-rays, which is fixed by creating a shadow projection - a graphic file in which each pixel contains information about the amount of absorption at a given point. The result of scanning is a series of shadow images of the sample in X-ray light, which are converted into three- 
dimensional images for further visual studies and morphometric analysis using special software $[9,10]$.

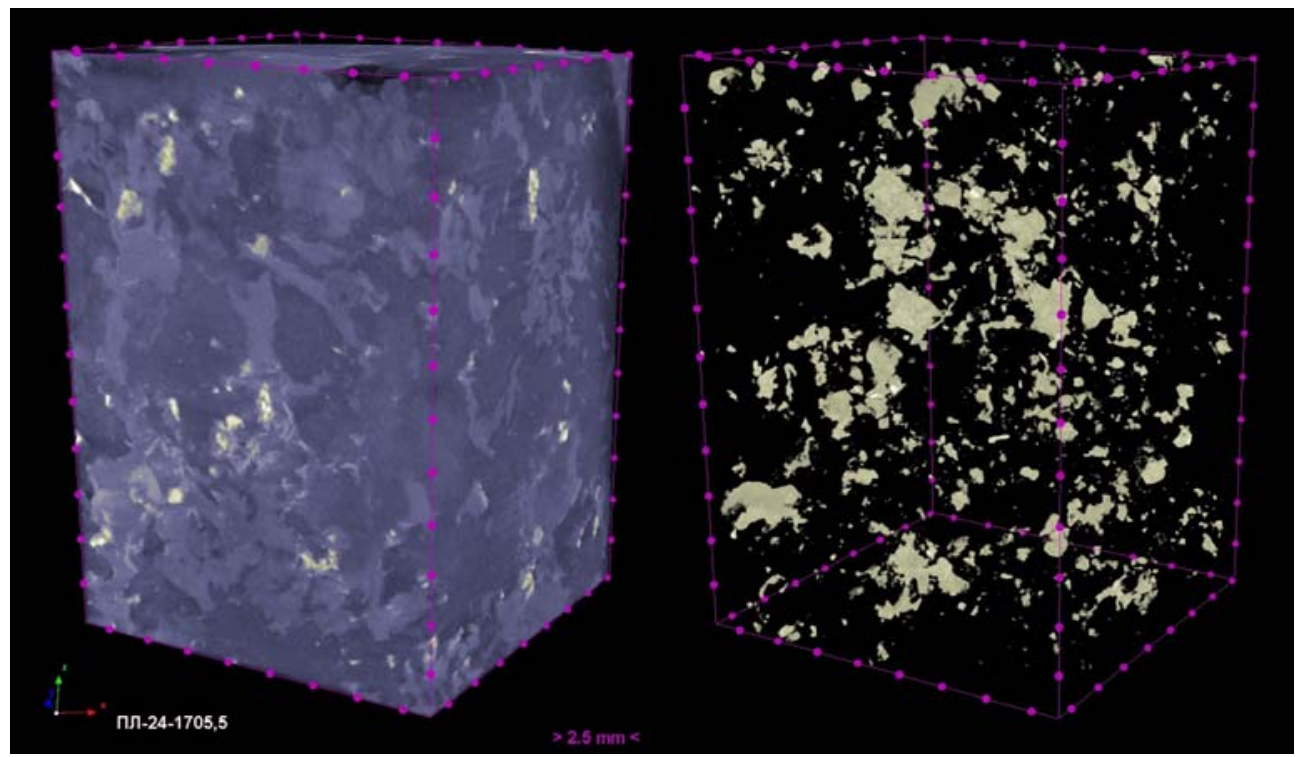

Fig. 1. 3D-visualization of a sample of copper-nickel ores (left) and the distribution of ore minerals in the volume of the rock (right)

Optical microscopic studies were carried out using a research-grade optical polarizing microscope Axio Imager A2m (Zeiss) and software for image analysis Thixomet Pro (Russia, SPbPU), which was certified as a measurement tool. For research, oriented petrographic thin sections were made along mutually perpendicular sections (Fig. 2).

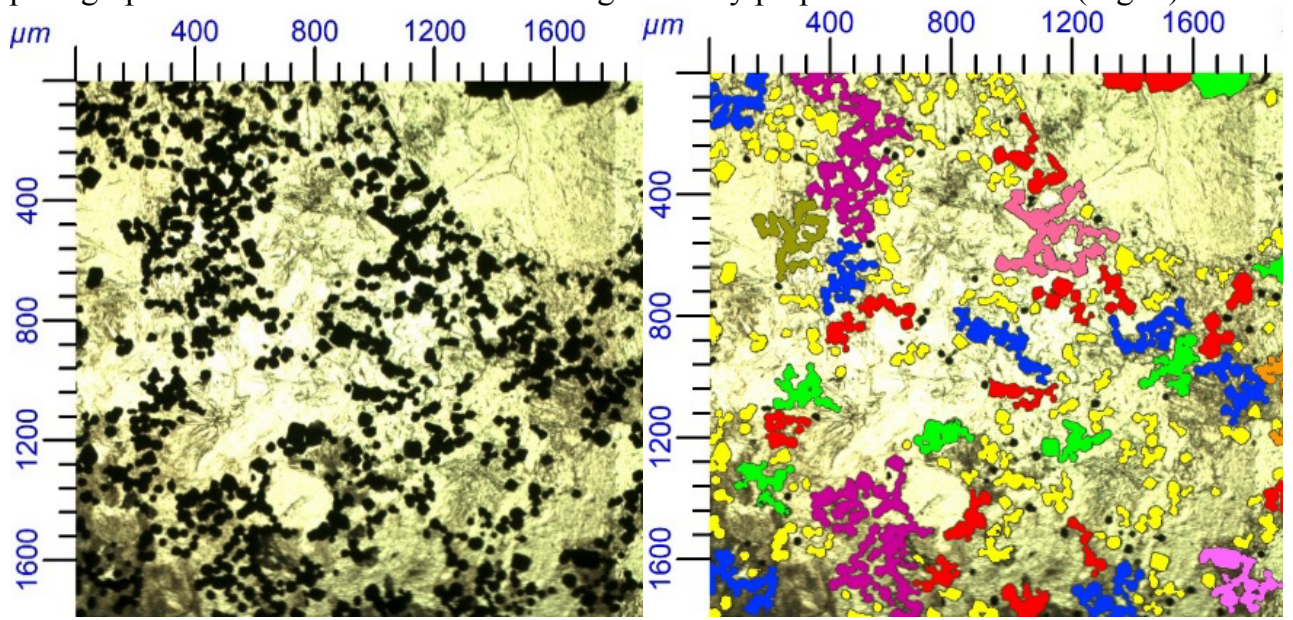

Fig. 2. An example of automatic image capture in Thixomet Pro. Ore minerals

\section{Results and discussion}

The methods of computer X-ray microtomography were used to study the morphometric parameters of the samples and to compare these data with the results of optical microscopic examination and data analysis in the Thixomet Pro image analysis software. The studies carried out made it possible to identify automatically 19 morphometric parameters of ore 
grains in three mutually perpendicular sections, the most informative of which were the grain size of ore minerals, their perimeter, the distance between grains and the shape of grains (sphericity, edge roughness, etc.).

For all analyzed minerals, a statistical analysis of their shape and size was performed. The shape of individual objects was assessed according to the following morphometric parameters: volume, surface area, diameter, sphericity (ratio S1/S2, where S2 is the surface of a particle and S1 is the surface of a sphere of the same volume). Also, both methods were used to determine the content of ore minerals (Table 1).

Table 1. Comparison of the ore mineral content in the sulfide ore samples according to the data of computer X-ray microtomography and optical microscopic determination.

\begin{tabular}{|c|c|c|}
\hline \multirow{2}{*}{ Sample No } & \multicolumn{2}{|c|}{ Content, $\%$} \\
\cline { 2 - 3 } & $\begin{array}{c}\text { According to X-ray } \\
\text { microtomography }\end{array}$ & $\begin{array}{c}\text { According to optical- } \\
\text { microscopic method }\end{array}$ \\
\hline 1 & 9,26 & 10 \\
\hline 2 & 6,13 & 6 \\
\hline 3 & 12,66 & 10 \\
\hline 4 & 5,18 & 5 \\
\hline 5 & 2,81 & 5 \\
\hline 6 & 5,42 & 4 \\
\hline 7 & 4,29 & 5 \\
\hline 8 & 10,94 & 10 \\
\hline 9 & 6,01 & 5 \\
\hline 10 & 5,09 & 5 \\
\hline 11 & 7,14 & 7 \\
\hline
\end{tabular}

One of the main limitations of the use of X-ray microtomography is that the tomograph results do not allow distinguishing mineral grains with a similar X-ray density. This method is most effective in distinguishing ore minerals with high X-ray density (native elements, sulfides and metal oxides) from silicate (olivine, pyroxenes, amphiboles, feldspars, quartz, etc.) or carbonate matrix.

A significant difference in the density of minerals among others plagioclase $\left(\approx 2.7 \mathrm{~g} / \mathrm{cm}^{3}\right)$, clinopyroxene $\left(3.1-3.5 \mathrm{~g} / \mathrm{cm}^{3}\right)$, sulfides (chalcopyrite $\sim 4.2 \mathrm{~g} / \mathrm{cm}^{3}$, pyrrhotite 4.6-4.7 g/cm3, ilmenite $4.8 \mathrm{~g} / \mathrm{cm}^{3}$, magnetite up to $5.2 \mathrm{~g} / \mathrm{cm}^{3}$, marcasite $4.85-4.9 \mathrm{~g} / \mathrm{cm}^{3}$, titanomagnetite $\left.4.8-5.3 \mathrm{~g} / \mathrm{cm}^{3}\right)$ and platinoids $\left(18-21 \mathrm{~g} / \mathrm{cm}^{3}\right)$ allows one to obtain a real picture of the distribution of the densest phases from several centimeters, up to 15-20 microns. Also, as a result of microtomographic studies, 3D images of the samples were obtained, and one can observe not only the size of ore grains and their aggregates, but also their distribution in the total volume of the rock and the relationship with each other.

\section{Conclusions}

As a result of the studies, morphostructural characteristics were determined, regularities of changes in the quantitative characteristics of various petrographic structures of intrusive rocks in ore-bearing intrusions along the section and lateral were revealed, and a threedimensional modeling of the internal structure of samples with sulfide mineralization was carried out. In the course of the work, methods of statistical processing of research data were used. The next step should be a theoretical substantiation of the relationship and mutual influence of mineralogical-geochemical, structural-textural and physical-technical 
properties of minerals that determine the opening of ore minerals in the processes of selective disintegration and separation.

The studies indicate the broad possibilities of both methods in solving scientific problems and practical tasks associated with the study of the physical and mechanical properties of rocks that determine the opening of ore minerals, the assessment of the content of ore minerals in them, the analysis of the granulometry and spatial distribution of their grains. The prospects of the method lie not only in the possibility of obtaining quantitative characteristics of mineral phases, the degree of fracturing and porosity of rocks, but also in the wide possibilities of $3 \mathrm{D}$ visualization of the data obtained with short time, which makes it possible to use this method in a wide range of studies, including in preparation rocks and ores to disintegration.

This work was carried out with financial support from the Russian Foundation for Basic Research (project No. 20-55-12002 / 20). The authors of the article express their gratitude to the developers of the Thixomet program, who provided software for calculating the quantitative indicators of the structural and textural parameters of ores and to the computer tomograph operator, engineer V.S. Nikiforova (St. Petersburg Mining University) for the performed tomographic sampling of the samples.

\section{References}

1. V.S. Litvinenko, Nat Resour Res 29, 1521-1541 (2020). https://doi.org/10.1007/s11053-019-09568-4

2. A. B. Makhovikov, E. V. Katuntsov, O. V. Kosarev, \& P. S. Tsvetkov, In Innovationbased development of the mineral resources sector: Challenges and prospects - 11th conference of the Russian-German Raw Materials (pp. 531-538). (2019)

3. T.N. Aleksandrova, N.V. Nikolaeva, V.V. Lvov, A.O. Romashev, Obogashchenie Rud 2, 8-13 (2019)

4. J. Benndorf, M. Buxton, Math Geosci 51, 845-847 (2019). https://doi.org/10.1007/s11004-019-09828-2

5. V.I. Revnivtsev. Preparation of mineral raw materials for enrichment and processing (Moscow: Nedra, 1987). In Russian

6. R.K. Ilalova, Y.L. Gulbin, Geol. Ore Deposits 61, 736-746 (2019). https://doi.org/10.1134/S107570151908004X

7. O. Popov, H. Lieberwirth, T. Folgner, AT Miner. Process. 07-08, 76-88 (2014)

8. M. Klichowicz. T. Frühwirt, H. Lieberwirth, Miner. Eng. 128, 312-323 (2018)

9. L.A. Weisberg, E.E. Kamenev, Yu.G. Pimenov, D.I. Sokolov, Beneficiation of ores, 3, 37-40 (2013). In Russian

10. A. Duryagina, I. Talovina, A. Shtyrlyaeva, O. Popov, Key Eng. Miner., 769, 220-226 (2018) 